\title{
The reuse of waste from road resurfacing: cold in-place recycling of bituminous pavement, an environmentally friendly alternative to conventional pavement rehabilitation methods
}

\author{
M. J. Martínez-Echevarría, M. C. Rubio \& A. Menendez \\ Department of Civil Engineering, University of Granada, Spain
}

\begin{abstract}
The conservation and maintenance of highways is an increasingly important activity in developed countries. Since it generates great quantities of inert waste material, an alternative use for this waste must be found so that it does not end up in landfills.

This paper examines the multiple benefits of cold in-place recycling (CIR) of bituminous pavement as compared to other more conventional pavement rehabilitation methods. It also analyzes the performance of CIR with a view to extending its use to more highway and vehicle traffic types.

CIR permits the reuse of existing material. This process involves milling and crushing the existing asphalt pavement, rejuvenating the cement, and finally placing and compacting the material to a specified depth. Consequently, it reduces the production of conventional aggregate, and thus, the extraction of virgin aggregate from natural quarries. CIT is preferable to other techniques because it saves energy as well as reduces contamination from gas emissions.

Key words: pavement rehabilitation, cold recycling, emulsion, environmental advantages, reuse.
\end{abstract}

\section{Introduction}

In recent years in a world increasingly under attack from pollution, the conservation of natural resources has become a top priority in all production sectors. The construction industry is also faced with this challenge, and has pioneered the development of new techniques for the reuse of the waste material 
that it generates. The success of this initiative is assured because of the quantity as well as the characteristics of this waste material, which makes recycling a viable option. Examples of this type of waste are the cement debris from the demolition of buildings, other construction debris, and the asphalt pavement removed during highway rehabilitation. Of another type, but also recyclable is the slag from steel mills, metal aggregate, and other inert waste products. If these materials are to be reused, they must first meet the technical and environmental specifications required by law, which classifies them for their use in various possible units In Spain, articles 330, 331 and 510 of the "Pliego de Prescripciones Técnicas Generales para Obras de Carreteras y Puentes" permits the reuse of products from industrial processes or handling, recycled granular material, metal aggregate, subproducts, and inert waste products as long as they meet the specifications in these articles and are in accordance with the National Program for Construction and Demolition Wastes [1].

In line with environmental policies, highway administrations in countries all over the world have become increasingly aware of the importance of prolonging the life cycle of road surface material by sponsoring programs that support the development of recycling techniques.

However, in Spain, as in many other countries, the construction of a new highway or the reinforcement and renovation of existing highways are carried out in most cases by blending mixtures of virgin aggregate and asphalt binder. This requires the exploitation of new quarries or the over-exploitation of existing ones, as well as the consumption of large quantities of new bitumen. All of these actions have a negative impact on the environment.

A frequent method of reinforcing and rehabilitating road surfaces is milling and crushing the old asphalt surface so that it can be replaced with a new layer. This process generates waste material, such as aggregate and asphalt binder, both of which have a high recycling potential. Unfortunately, instead of being reused, this material is often dumped at landfills, thus becoming a source of pollution.

A solution for such waste disposal problems is the use of recycling techniques, which are very beneficial because of their environmental friendliness. In Spain hot recycling came into use at the beginning of the 1980s. After 1991, cold recycling appeared on the scene. This recycling method processes existing pavement with the addition of bitumen emulsion as well as cement. Over the years cold recycling methods have been refined and improved. As a result, cold recycling has become increasingly popular because of the advantages that it offers in comparison to other recycling techniques [2].

\section{Description}

The recycling of materials in highway construction and rehabilitation is an excellent way to avoid using new material and reduce quarry exploitation. When material is recycled, waste dumping falls to minimal levels. In many countries dumping such waste at landfills is increasingly difficult due to lack of space and strict environmental regulations that many governments are currently imposing. 
Recycling techniques have evolved rapidly in countries such as the United States, Australia, Germany, and France. As previously mentioned, Spain has over a decade of experience in the recycling of asphalt pavement. The equipment and machinery for this technique have become more and more efficient and specialized $[3,4]$.

The recycling of road surface material includes a series of construction methods designed for the integral exploitation of old material reclaimed from road surfacing and pavement. It is possible to carry this process out on site, or alternatively, by transferring reclaimed asphalt pavement (RAP) to a processing plant. In both cases, pavement recycling can be divided into two general categories, based on the methods used: hot recycling and cold recycling.

\subsection{In-plant recycling of bituminous levels}

\subsubsection{Hot recycling}

Hot recycling is the process of combining reclaimed asphalt pavement (RAP) with new aggregates and asphalt binder to produce recycled hot mix asphalt (HMA), which has proved to be at least as effective as conventional HMA mixes. This is carried out after a preliminary process of homogenization or breaking down the reclaimed pavement into aggregate-sized chunks.

Conventional batch plants can recycle up to $10 \%$ of the RAP, introduced into the boot of the hot elevator. Higher percentages of RAP require specific technologies for this process in continuous as well as batch plants. RAP characteristics must also be strictly monitored. When there is a higher percentage of RAP and old binders, rejuvenating agents must be used in the new binder.

\subsubsection{Cold recycling}

Cold recycling is the rehabilitation of asphalt pavements without the application of heat during the recycling process. The process involves using old HMA pavement and mixing it with emulsion (sometimes also with lime or cement and virgin aggregate in order to correct particle size) in situ or in a central plant to produce cold mix asphalts, similar to Gravel Emulsion.

\subsection{In-place recycling}

\subsubsection{Hot in-place recycling (HIPR) of bituminous pavements}

HIPR rehabilitates the wearing course or road surface to a depth of $3-8 \mathrm{cms}$ to repair deteriorated pavement (aggregate polishing, texture, cracking because of binder aging, longitudinal or transversal regularity). As it only affects the surface layer, it is applied when there are no structural problems because of its limited reinforcement capacity. The first phase in the process is to soften the asphalt pavement surface by heating it to a temperature of between $120^{\circ} \mathrm{C}$ and $160^{\circ} \mathrm{C}$ to facilitate the scarification of the pavement surface. This avoids degradation of aggregate and particle size, which can occur during milling. The next step is the mixing and subsequent homogenization of the resulting material with asphalt binders, aggregate or bituminous mix. This treatment is only viable for shallow 
levels because if a maximum surface temperature is surpassed, there is the risk of binder deterioration as well as smoke emissions.

\subsubsection{Cold recycling}

The material is loosened from the compacted layer and mixed on site with an asphalt binder. It is thus not necessary to transfer it to a central plant. The final quality depends largely on the homogeneousness of the road layer treated.

Cold in-place recycling (CIR) with bitumen emulsion is a technique used to transform a deteriorated road surface into a homogeneous structure that is well adapted to the volume of vehicle traffic. It consists of reusing existing pavement (RAP) to produce a restored pavement layer by crushing it to the required gradation. The RAP is blended with a binder (usually emulsified asphalt or cement), water (to hydrate and compact the mix), fresh aggregate (to correct particle size), and in some cases, other additives. The material is mixed at the site, placed back over the previously milled pavement, compacted to the desired density, and left for curing. This creates a surface level of greater structural resistance. Although there are different CIR methods, all include the following operational phases:

$>$ Milling of the original pavement

$>$ Injection of emulsion and water

$>$ Mixing and homogenization

$>$ Mixture placement

$>$ Compaction

\begin{tabular}{|l|l|}
\hline Término en español & English Translation \\
\hline Esquema de un equipo de reciclado & Diagram of a recycling train \\
\hline Sentido de avance & Forward direction \\
\hline $\begin{array}{l}\text { Inyección de agua, emulsión o lechada de } \\
\text { cemento }\end{array}$ & $\begin{array}{l}\text { injection of water, emulsion or cement } \\
\text { slurry }\end{array}$ \\
\hline Árido de aportación (donde sea preciso) & virgin aggregate (where necessary) \\
\hline Regla de extensión & paving screed \\
\hline Tornillo de reparto & distribution augur \\
\hline Fresadora & milling machine \\
\hline Regla de control & control ruler \\
\hline Capa reciclada & recycled pavement layer \\
\hline Pavimento deteriorado & deteriorated pavement \\
\hline
\end{tabular}

If it is necessary to modify the particle size of the aggregate to be recycled, the necessary quantity of new aggregate is laid out on the pavement surface since afterwards it will be mixed with the reclaimed asphalt pavement during the milling process.

The CIR recycling train mills a thin surface layer of the pavement, injects water and emulsion, and creates a homogeneous mix. This is distributed by means of a distribution augur and laid out on the surface with a paving screed.

After this process, compaction is carried out by conventional heavy equipment for this purpose. The highway can be opened to vehicle traffic immediately after the recycling process. It is necessary to wait at least three 
weeks before laying out the wearing course. This gives time for curing to take place. During this period, the recycled material can be used as a provisional road surface. If necessary, slurry seal can also be applied $[5,6]$.

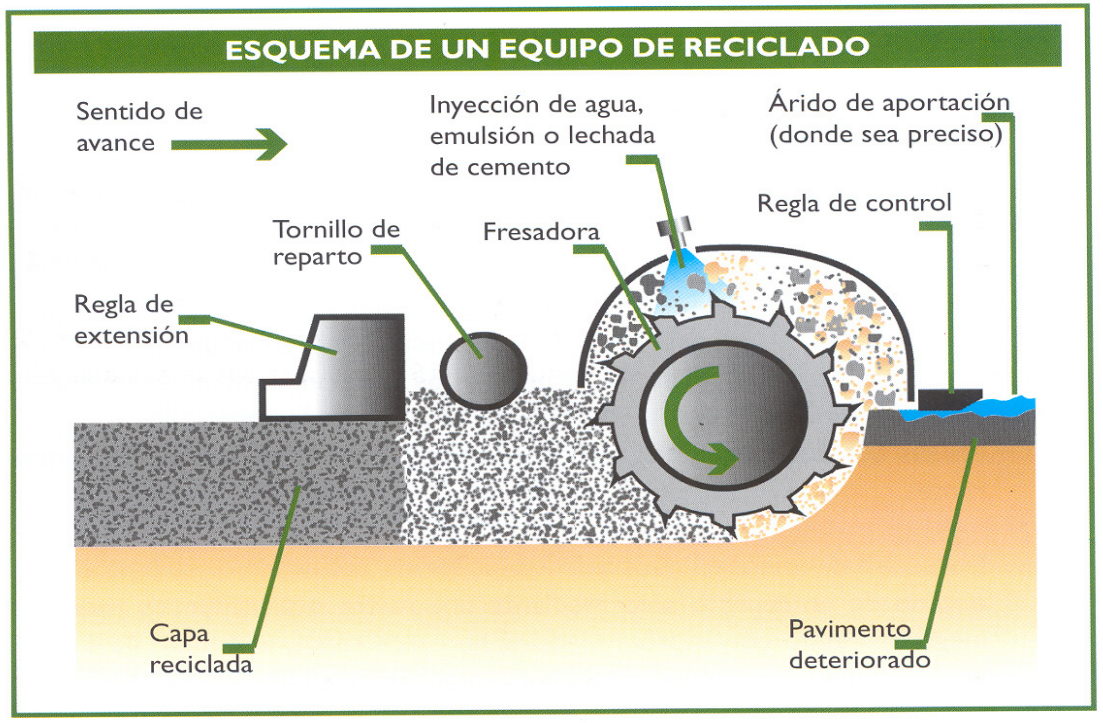

Figure 1: $\quad$ Recycling process. Sacyr. Tecnología Mayo 2003.

\section{Advantages of CIR}

The advantages of CIR are mainly environmental, but there are other advantages as well:

\subsection{Environmental advantages}

- Minimal environmental impact on the area where the road work is being carried out

Existing material from the old highway is reused without the necessity of exploiting new quarries or waste dumping.

\section{- Lower noise level}

Since old pavement is reused without using virgin aggregate or mix, there is less hauling of materials. The reduction in the transit of heavy vehicles signifies less noise.

\section{- Reduction in greenhouse gas emission}

The reduction in heavy vehicle traffic also produces fewer greenhouse gas emissions. 


\section{- Reduction in energy consumption}

Since there is no need to heat the bituminous mix, there is no consumption of fossil fuel, and consequently, there is a reduction in $\mathrm{CO}_{2}$ emissions.

\subsection{Operational advantages}

\section{- Decrease of collateral deterioration in adjoining highways}

The decrease in hauling materials positively affects adjoining highways, which are thus not subject to possible deterioration because of heavy vehicle traffic

- Reduction in traffic disturbance during construction

All of the work can be carried out with the same machine. In a single pass it mills the deteriorated pavement, mixes it with the binder, and lays down the final mix on the existing surface. This reduces the possible stoppage and damage to the main part of the road from the weight and transit of the machinery.

- Virtually no traffic interruption. The road can be opened again immediately after the recycling work has finished.

\section{- Increase in work safety}

Since only one machine is involved and the highway is reopened to vehicle traffic almost immediately after the work is finished, there is a substantial increase in worker and vehicle safety.

\subsection{Technical advantages}

- Possibility of working on a single traffic lane

Heavy vehicle lanes and ordinary vehicle lanes can each receive specific treatments, tailored to their needs. For example, pavement reinforcement can be eliminated in lanes for normal vehicles.

- The geometric characteristics of existing infrastructures are maintained

Since CIR involves in-place recycling of the pavement of an old, deteriorated highway, horizontal and vertical loading gauges are preserved, thus respecting the original geometry of the highway. This point is important in stretches of highway located beneath overhead passes and over underpasses, intersections at different levels, and tunnels $[5,6]$.

\section{Limitations of CIR}

Despite its many benefits, cold in-place recycling with bitumen emulsion is a process that has the following limitations: 
- Not all materials can be recycled effectively and economically. Similarly to other conservation techniques, pavement recycling projects require an in-depth study of sites and materials.

- Recycling cannot solve certain types of road surface problems, particularly those associated with the deficient quality of the surface and underlying levels. Nor can it easily solve problems related to structural deformation/distortion. When possible, aggregate from another source may have to be used for the correct gradation of the mix.

- It is not a good idea to recycle pavements that contain geotextiles for the prevention of reflective cracking. When these geotextiles are located at the same depth as the material to be recycled, their subsequent disintegration is complicated. Pieces of geotextile may appear on the surface, and can easily become detached. The quality of the resulting mix is poor, and its functionality is low.

- In the same way as any other process using bituminous material, CIR is dependent on weather conditions. Consequently, it is not advisable to carry out cold in-place recycling with bitumen emulsion during the rainy season or during winter months when temperatures are very low [7].

\section{Legal framework}

The Ministerio de Fomento [Ministry of Public Works in Spain] has established regulations regarding recycling. They are described in the PG4 (Pliego de Prescripciones Técnicas Generales para Obras de Conservación de Carreteras/ General Technical Requirements for Highway Conservation Work), article 20, Reciclado in situ con emulsión de capas bituminosas, (In-place recycling with bitumen emulsion), in force since January 18, 2002, according to Circular $8 / 2001$. Cold in-place recycling with bitumen emulsion is also mentioned in Regulation 6.3 IC Rehabilitación de firmes (Pavement recycling), regulated by FOM Order 3459/03, November 28, 2003.

Regional governments in Spain also have passed the following legislation regarding CIR:

- Regulations for the design of road surfacing in the Andalusian highway network, 1999

- Recommendations for the design and construction of road surfacing and pavement. Junta de Castilla y León [Regional Government of Castilla and Leon], 2004

As can be observed, the passing of legislation regarding CIR has lagged far behind the actual use of the technique. However, the appearance of laws, regulations, and recommendations is very positive since such measures offer a safety guarantee for administrations who wish to use this process, and assure the quality control of the product on highways. 


\section{Project design and implementation of cold in-place recycling with bituminous emulsion $[8,9]$}

The project design of in-place recycling with bituminous emulsion requires an in-depth study for two reasons: (i) the characteristics of the material to be treated may vary along the highway. It is thus necessary to be aware of such differences in order to take them into account during the recycling project; (ii) RAP is a mix of aggregate and old asphalt binder, which may behave somewhat differently from conventional aggregate.

Generally speaking, the project design phase should include the following:

a. Data collection. In the same way as any other project design, the first step is a visual inspection of the terrain, and the extraction of specimens, and milling samples. This is followed by an analysis of existing material, probing and deflections. The characteristics of the bitumen should also be analyzed and described.

b. After data collection, depths are calculated by inverse calculation. The material from these levels is used to make test specimens, which vary, depending on the binder used. The optimal amount of binder should be determined as well as the quantity of water necessary for the mix. Inverse calculation operates on the premise that the material to be recycled has an elasticity modulus and a Poisson coefficient. Accordingly, it is possible to calculate the depths, fulfilling all requirements. Once the project has actually begun, it is necessary to verify that the Poisson coefficient as well as the elasticity modulus coincide with or are better than the previously calculated values. The depth of the level can be increased or decreased, accordingly.

c. Once the data is collected and the depths defined, the budget can be made out. The recycling technique to be used can be compared with other more conventional ones with a view to evaluating its economic viability, and thus deciding if it is the most appropriate.

The study of the implementation of pavement recycling includes the following phases:

- Definition of homogeneous sections

- Examination of the road surface

- Analysis of the emulsion

- $\quad$ Study of the water that needs to be added

- Study of additional material to be used, if relevant

- Design of the project plan

- $\quad$ Section testing

- $\quad$ Implementation and monitoring of the road work

\subsection{Definition of homogeneous sections}

The first step is the definition of homogeneous highway sections. This means previously specifying vehicle traffic and climate as well as the condition of the 
existing pavement. For this reason, it is necessary to collect historical data related to construction, road widening, reinforcement, etc. Furthermore, apart from structural monitoring data, which should also be available, it is absolutely imperative to carry out a visual inspection of the road section.

This information will be used to define sections (always less than $10 \mathrm{kms}$ ), characterized by the homogeneousness of their longitudinal and transversal structure, more specifically in everything referring to the depth of levels, types of material, types and degree of deterioration (potholes, alligator cracking, bleeding, etc.).

\subsection{Examination of the existing road surface}

Once the homogeneous highway sections are defined, it is then necessary to collect samples of the material in each section. The samples will not be limited to a single point. Rather it is necessary to take various samples for each section. The samples obtained should be analyzed in the laboratory. When necessary, the results obtained should be used to redefine the homogeneous sections defined in the initial phase. Samples should be collected in the following way:

- Extraction of specimens

Specimens are taken in order to determine depths, the content of residual binder, and the densities of existing layers. This density calculation will be subsequently used to establish the final compacting of the recycled level, which will correspond to a specific percentage of the level before milling.

- $\quad$ Milled material

The samples should be obtained by the same type of operation that will be used in the pavement rehabilitation process. As a rule, this means that samples should be obtained by milling, and moreover, with the same type of machine used in the road work so that they will be representative. The tests to be carried out are those related to particle size before and after the extraction of bitumen, as well as to content and type of binder (e.g. penetration, and ring and ball softening point). At least one sample should be taken per section, and a minimum of two samples for each project.

\subsection{Analysis of the emulsion}

It is always advisable to use slow-setting emulsions. In this case, the following analyses should be carried: particle load, water content, residue and flow aid by distillation, penetration of the residue, Saybolt-Furol Viscosity at $25^{\circ} \mathrm{C}$, ductility, screening, and stability of anionic emulsions with cement.

\subsection{Study of the pre-mix water}

The water used in the recycling should fulfill the requirements in article 280 of the PG-3. 


\subsection{Study of added material}

The characteristics of this material will be defined by the specifications of the recycled level.

\subsection{Design of the project plan}

The design parameter is the immersion-compression test. The optimal percentage of the binder content should be that which fulfills the legal requirements for the immersion - compression test, and obtains the maximum value in the compressive strength of wet specimens.

The project plan should include:

- Gradation of the milled material, percentage of the water for the mix; size correction of the aggregate, if necessary; type and quantity of additives (cement and/or lime) when necessary; type of bituminous emulsion and percentage regarding dry aggregate which will satisfy the specifications defined in the project design; Modified Proctor test, which should be carried out on the mix of milled material and the emulsion.

\subsection{Section testing}

Before beginning the road work project, and once the project plan has been approved, tests should be carried out on parts of each homogeneous section. The test should be carried out with the same machinery to be used in the actual road work.

\subsection{Implementation and monitoring of the road work}

The work will finally be carried according to the specifications obtained from the test sections (speed of the milling machine, change of cutters, compacting criteria, etc.). The results of quality control tests will be used to verify the correct operation of all aspects of the recycling process. In the case of anomalous results, the process should be reassessed, and the project plan modified accordingly.

\section{Conclusions}

Based on the advantages listed in section 3 and considering the conservation and maintenance work necessary during the useful life of a highway, we can affirm that cold in-place recycling of bituminous pavement is a very effective and environmentally friendly way of preserving the highway network in optimal condition.

\section{References}

[1] Vegas, I., Ibáñez, J.A., San José, J.T., Urzelai, A., (2008). "Construction demolition wastes, Waelz slag and MSWI bottom ash: A comparative 
technical análisis as material for road construction”. Waste Management 28. pp. 564-574. Elsevier

[2] Almazán D., (2008). "Tecnología e innovación el reciclado en frío de carreteras". III Jornada Nacional de Asefma. Asefma

[3] Alarcón, J. (2003). Estudio del comportamiento de mezclas bituminosas recicladas en caliente en planta. UPC. pp. 9-30.

[4] Karlsson, R., Isacson, U. (2006). Material-Related Aspects of Asphalt Recycling-State-of-the-Art. J. Mat. in Civ. Engrg. Pp.18-81. ASCE

[5] Sacyr Tecnología (2003). Sacyr

[6] Almazán, D. (2007). "Reciclado en frío "in situ" con emulsión: pasado, presente y futuro de la técnica. IV Congreso Andaluz de Carreteras. Asociación Española de la Carretera

[7] Potti, JJ., Martínez, M. (2006). Evolución histórica de los reciclados in situ con emulsión. VII Congreso Nacional de Firmes. Asociación Española de la Carretera

[8] Bardesí, A. J (2000) Control de mezclas en frío y reciclados. Jornada sobre caracterización y control de calidad de mezclas bituminosas. Chapter 4 . Cedex

[9] Giasa (2004). Pliego para reciclado de capas de M.B.C. en frío "in situ" con emulsión bituminosa. Giasa, Consejería de Obras Públicas 